\title{
Are sodium and potassium results on arterial blood gas analyzer equivalent to those on electrolyte analyzer?
}

\author{
Shalini Gupta, Ashwani K. Gupta', Kamaljit Singh, Minni Verma
}

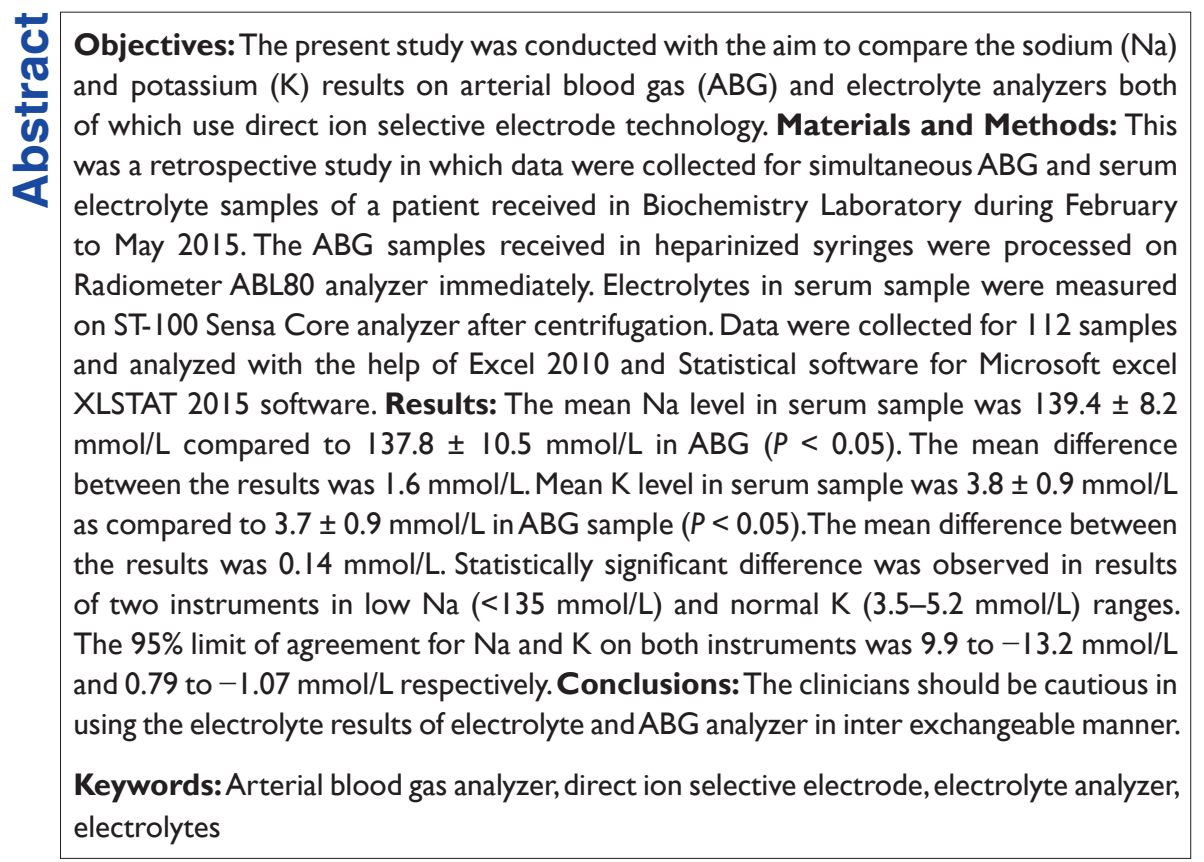

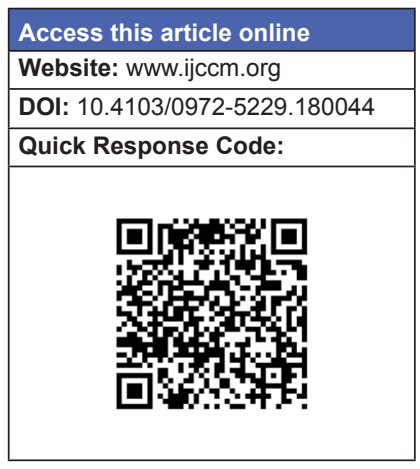

\section{Introduction}

Electrolytes are measured in the clinical laboratories In both serum and whole blood sample received for arterial blood gas (ABG) analysis. Although the routine practice is to measure electrolytes in serum, it takes relatively more time due to requirement of separation of serum. Emergency and critical care physicians prefer measurement of electrolytes along with blood gas analysis, which helps them in diagnosis and monitoring of electrolyte imbalance in a short turnaround time. It can

\section{From:}

Departments of Biochemistry and ${ }^{1}$ Pharmacology, Gian Sagar Medical

College and Hospital, Patiala, Punjab, India

\section{Correspondence:}

Dr. Shalini Gupta, Department of Biochemistry, Gian Sagar Medical College and Hospital, Ramnagar, Patiala - 140 401, Punjab, India.

E-mail: shalinidr2000@gmail.com play vital role in timely patient management by saving precious minutes.

Ion selective electrodes (ISEs) are the most routinely used method for electrolytes estimation in clinical laboratories. There are two types of ISE measurements based on sample preparation. Devices based on direct

This is an open access article distributed under the terms of the Creative Commons Attribution-NonCommercial-ShareAlike 3.0 License, which allows others to remix, tweak, and build upon the work non-commercially, as long as the author is credited and the new creations are licensed under the identical terms.

For reprints contact: reprints@ medknow.com

How to cite this article: Gupta S, Gupta AK, Singh K, Verma M. Are sodium and potassium results on arterial blood gas analyzer equivalent to those on electrolyte analyzer?. Indian J Crit Care Med 2016;20:233-7. 
measurement provide an undiluted sample to interact with ISE membrane. ${ }^{[1]}$ These direct ISE based devices are typical of point of care testing analyzers, both bench top and portable. ${ }^{[2]}$ The devices based on indirect ISE use preanalytic dilution and are often employed in high throughput central laboratory running automated analyzer. ${ }^{[3]}$

There is no consensus on inter exchangeability of results of these analyzers as studies using different devices have reported different results. ${ }^{[2-6]}$ It is, therefore, important to determine the concordance of electrolyte values obtained by $A B G$ and serum sample for each hospital as analyzer type and calibration methods may differ among different laboratories. ${ }^{[3]}$ Moreover, there is paucity of literature comparing the results of electrolytes in an arterial sample processed on ABG analyzer and serum sample processed on a bench top electrolyte analyzer both of which use direct ISE method without any need of predilution of sample.

The present study was planned with the objective to investigate whether electrolyte levels assessed using ABG analyzer and electrolyte analyzer were equivalent. Data on sodium $\left(\mathrm{Na}^{+}\right)$and potassium $\left(\mathrm{K}^{+}\right)$ion concentrations were examined on whole blood arterial, and serum samples received simultaneously in laboratory.

\section{Materials and Methods}

This was a retrospective observational study conducted for the period February to May 2015 in the Biochemistry Laboratory of a tertiary care hospital. The study was approved by Institutional Ethical Committee (Gian Sagar Medical College and Hospital, Punjab, India). A record of simultaneous ABG and serum electrolytes samples of a patient received in the laboratory was collected. The samples received from emergency and Intensive Care Units (ICU) were included in the study. The samples from pediatric and neonatal ICUs were excluded from the data. The serum sample was obtained by withdrawing $3 \mathrm{ml}$ of venous blood in BD plain vacutainer (Becton Dickinson and Company, Franklin Lakes, USA) under aseptic conditions. The arterial sample was collected in a $2 \mathrm{ml}$ Dispovan syringe (Hindustan Syringes and Medical Devices, Ballabgarh, India) under sterile environment using standard sampling protocol. The syringe was flushed thoroughly with $1 \mathrm{ml}$ solution of liquid heparin (Zydus Cadila Healthcare Limited, Gujarat, India) which was removed completely before drawing of the sample. Quality control was ensured by having the blood samples collected by trained staff of emergency and ICU in the hospital and analyzed on two analyzers located in the central laboratory under similar environmental conditions. ABG samples received in heparinized syringes were processed on Radiometer ABL 80 analyzer (Diamond Diagnostics, USA) immediately for electrolytes along with blood gases.

The samples received in $\mathrm{BD}$ vacutainer for serum were centrifuged within 20-30 min after clotting of blood. Electrolytes were measured on ST 100 electrolyte analyzer (Sensacore medical Instrumentation Pvt Ltd, India). Both these instruments work on the principle of direct ISE technology. The inter instrument comparison of electrolytes done on 30 serum samples in February 2015 had produced comparable results. The mean bias was 0.5 $\mathrm{mmol} / \mathrm{L}$ and $0.01 \mathrm{mmol} / \mathrm{L}$ for $\mathrm{Na}^{+}$and $\mathrm{K}^{+}$respectively on Radiometer analyzer as compared to Sensa Core electrolyte analyzer. The internal quality control was run daily on both the instruments during the study period. The mean $\mathrm{Na}$ was $123.5 \mathrm{mmol} / \mathrm{L}$ and $147.1 \mathrm{mmol} / \mathrm{L}$ for the concentration of $124 \mathrm{mmol} / \mathrm{L}(112-136 \mathrm{mmol} / \mathrm{L})$ and $148 \mathrm{mmol} / \mathrm{L}(133-163 \mathrm{mmol} / \mathrm{L})$ respectively on electrolyte analyzer and $122.9 \mathrm{mmol} / \mathrm{L}$ and $146.7 \mathrm{mmol} / \mathrm{L}$ on ABG analyzer. The mean $\mathrm{K}$ was $3.5 \mathrm{mmol} / \mathrm{L}$ and $6.7 \mathrm{mmol} / \mathrm{L}$ for concentrations of $3.68 \mathrm{mmol} / \mathrm{L}(3.22-4.04 \mathrm{mmol} / \mathrm{L})$ and $6.85(6.17-7.53) \mathrm{mmol} / \mathrm{L}$, respectively, on electrolyte analyzer and $3.5 \mathrm{mmol} / \mathrm{L}$ and $6.72 \mathrm{mmol} / \mathrm{L}$ on ABG analyzer. The measurement uncertainty of Sensa Core electrolyte analyzer was $1.9 \mathrm{mmol} / \mathrm{L}$ and $0.16 \mathrm{mmol} / \mathrm{L}$ for $\mathrm{Na}^{+}$and $\mathrm{K}^{+}$, respectively. The measurement uncertainty values were $2.3 \mathrm{mmol} / \mathrm{L}$ and $0.25 \mathrm{mmol} / \mathrm{L}$, respectively, for $\mathrm{Na}^{+}$and $\mathrm{K}^{+}$for $\mathrm{ABG}$ analyzer.

The reference ranges for $\mathrm{Na}^{+}$and $\mathrm{K}^{+}$were 135-145 mmol/L and 3.5-5.2 mmol/L, respectively. Data were rearranged as low, normal, and high according to the reference range and comparison of results was done on both the analyzers.

\section{Statistical analysis}

A total of 112 simultaneous ABG and serum samples were received during the study period. The data were collected and arranged in tables using Microsoft Excel 2010. Mean, standard deviation and two-tailed $P$ value was calculated. $P<0.05$ was considered statistically significant. Bland-Altman plots were used for inter instrument comparison of results.

\section{Results}

The mean age of the patients was 49.5 years. There were 86 male and 26 female patients in the study. The mean level of $\mathrm{Na}$ in serum samples was $139.4 \pm 8.2 \mathrm{mmol} / \mathrm{L}$ compared to137. $\pm 10.5 \mathrm{mmol} / \mathrm{L}$ in ABG $(P<0.05)$ [Table 1]. The mean difference among the results was $1.6 \mathrm{mmol} / \mathrm{L}$ showing a negative bias in 
arterial sample. Wide variations in Na results among individual samples were observed which ranged from 13 to $-33 \mathrm{mmol} / \mathrm{L}$ [Figure 1]. There were 75 samples with variation up to $4 \mathrm{mmol} / \mathrm{L}$ which is acceptable limit for $\mathrm{Na}^{+}$as per Clinical Laboratories Improvement Amendment (CLIA) guidelines. ${ }^{[7]}$

Mean $\mathrm{K}$ in serum sample was $3.8 \pm 0.9 \mathrm{mmol} / \mathrm{L}$ as compared to $3.7 \pm 0.9 \mathrm{mmol} / \mathrm{L}$ in ABG sample $(P<0.05)$ [Table 1]. The mean difference was $0.14 \mathrm{mmol} / \mathrm{L}$ and ranged from -1.1 to $1.3 \mathrm{mmol} / \mathrm{L}$ [Figure 2]. There were 72 samples in the study with acceptable variation of up to $0.5 \mathrm{mmol} / \mathrm{L}$ as per CLIA recommendations for $\mathrm{K}$.

There was statistically significant difference in results among two instruments in low range of $\mathrm{Na}^{+}(<135 \mathrm{mmol} / \mathrm{L})$ and normal $\mathrm{K}^{+}$values (3.5-5.5 mmol/L) [Table 2].

\section{Discussion}

Electrolyte abnormalities are one of the common reversible causes of morbidity and mortality in patients admitted in ICUs. The levels of electrolytes need to be monitored on regular basis in these patients which are ordered in ABG or serum sample as per the convenience of sampling and requirement. The results of both types of measurement are used in inter exchangeable manner

Table I: Comparison of results in arterial and serum samples

\begin{tabular}{lcccc}
\hline $\begin{array}{l}\text { Mean } \pm \text { SD } \\
(n=I / 2)\end{array}$ & Serum sample & ABG sample & $\begin{array}{c}\text { Mean } \\
\text { difference } \pm \text { SD } \\
\text { (mmol/L) }\end{array}$ & $P$ \\
\hline $\mathrm{Na}^{+}(\mathrm{mmol} / \mathrm{L})$ & $139.4 \pm 8.2$ & $137.8 \pm 10.5$ & $1.6 \pm 5.9$ & 0.0042 \\
$\mathrm{~K}^{+}(\mathrm{mmol} / \mathrm{L})$ & $3.8 \pm 0.9$ & $3.7 \pm 0.9$ & $0.14 \pm 0.5$ & 0.0022 \\
\hline
\end{tabular}

There was statistically significant difference in mean results of $\mathrm{Na}^{+}$and $\mathrm{K}^{+}$on serum and ABG samples. SD: Standard deviation; Na: Sodium; K: Potassium; ABG: Arterial blood gas

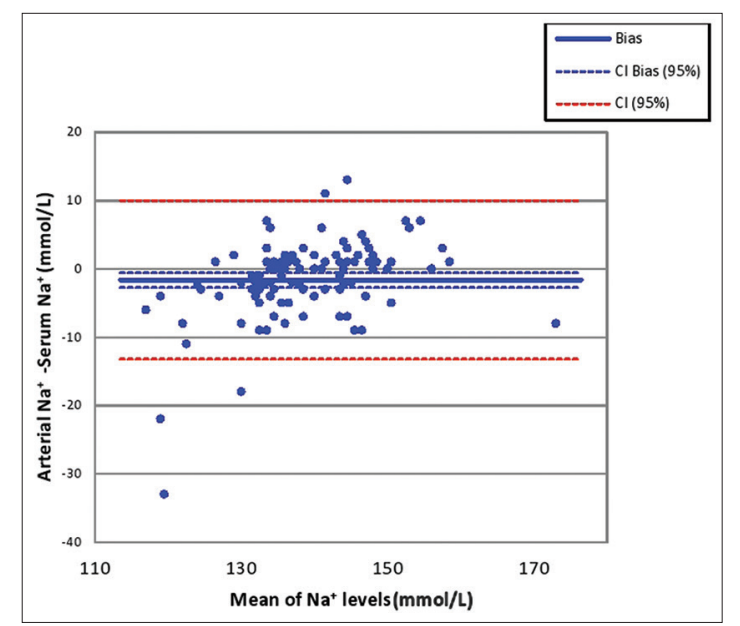

Figure I: Bland-Altman plot for $\mathrm{Na}^{+}$results in serum and arterial sample. The bias in arterial $\mathrm{Na}^{+}$measurement is $-1.63 \mathrm{mmol} / \mathrm{L}$. The $95 \%$ limit of agreement is 9.9 to $-13.2 \mathrm{mmol} / \mathrm{L}$. Na: Sodium with the assumption that they are equivalent. $\mathrm{Na}$ and $\mathrm{K}$ levels measured in whole blood and plasma have been shown to be essentially same ${ }^{[8]}$ though release of $\mathrm{K}$ from platelets during clotting may cause statistically insignificant increase of levels in serum. ${ }^{[5]}$

The most important factor which leads to difference in the results of $\mathrm{Na}^{+}$on $\mathrm{ABG}$ and laboratory autoanalyzer is predilution of sample in latter. The studies have reported statistically significantly higher results with indirect ISE based laboratory auto analyzers as compared to ABG analyzer. ${ }^{[2-4,9-12]}$ This overestimation is clearly linked to serum protein and albumin levels. Story et al. have reported that indirect ISE leads to overestimation of $\mathrm{Na}$ in hypoalbuminemia. The difference between direct and indirect ISE results was found to correlate with serum albumin and total protein concentrations. ${ }^{[9,13]}$

The use of different techniques was not a limitation in the present study as we compared results of two instruments using direct ISE method. We found statistically significant difference in mean values for $\mathrm{Na}^{+}$results with a negative bias of $1.63 \mathrm{mmol} / \mathrm{L}$ in arterial sample. The bias for $\mathrm{Na}^{+}$was reported to be 4.9 and $5.96 \mathrm{mmol} / \mathrm{L}$, respectively, in other studies which is higher than the acceptable limit of $4 \mathrm{mmol} / \mathrm{L}^{[3,4]}$ Another study comparing the result of two direct ISE based instruments has reported the mean difference in $\mathrm{Na}$ results as $3 \mathrm{mmol} / \mathrm{L}$ and found the correlation coefficient of $0.787 . .^{[6]}$ In the present study, both instruments had acceptable Spearman's correlation coefficient of $r_{\mathrm{s}}=0.846$ for $\mathrm{Na}$ but the Bland-Altman plot shows the inter analyzer agreement unacceptable with limit of agreement of 9.9 to $-13.2 \mathrm{mmol} / \mathrm{L}$ [Figure 1].

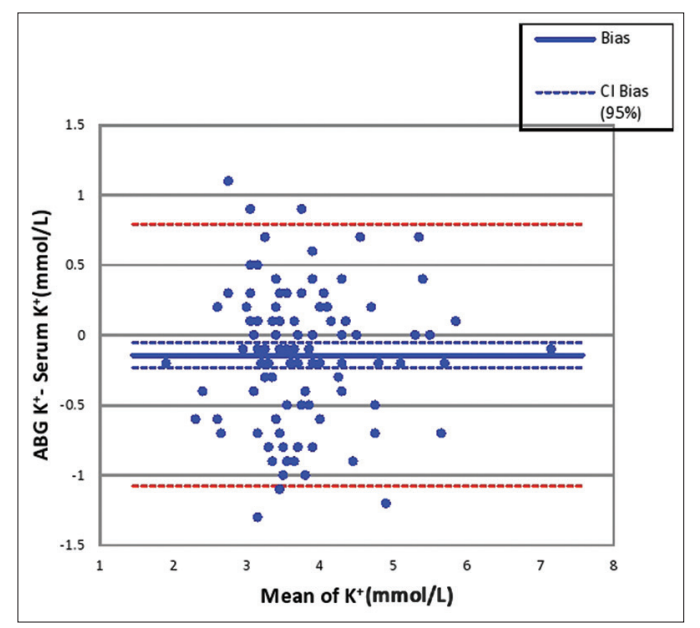

Figure 2: Bland-Altman plot for $\mathrm{K}^{+}$results in serum and arterial sample. The bias in arterial $\mathrm{K}^{+}$measurement is $-0.14 \mathrm{mmol} / \mathrm{L}$. The $95 \%$ limit of agreement is 0.79 to $-1.07 \mathrm{mmol} / \mathrm{L}$. K: Potassium 


\begin{tabular}{|c|c|c|c|c|c|c|}
\hline $\begin{array}{l}\text { Parameter value } \\
\text { (mmol/L) }\end{array}$ & $\begin{array}{l}n \text { (number } \\
\text { of samples) }\end{array}$ & Serum sample & ABG sample & Mean difference & Range of difference & $P$ \\
\hline & \multicolumn{6}{|c|}{$\mathrm{Na}^{+}$} \\
\hline$<135$ & 29 & $130.1 \pm 3.9$ & $127.7 \pm 7.6$ & 2.4 & $7--22$ & $0.0325^{*}$ \\
\hline $135-145$ & 60 & $139.5 \pm 3.3$ & $138.2 \pm 7.3$ & 1.3 & $13-33$ & 0.1155 \\
\hline \multirow[t]{2}{*}{$>145$} & 23 & $151.0 \pm 6.4$ & $149.5 \pm 7.4$ & 1.5 & $7--9$ & 0.1782 \\
\hline & \multicolumn{6}{|c|}{$\mathbf{K}^{+}$} \\
\hline$<3.5$ & 41 & $3.0 \pm 0.3$ & $3.1 \pm 0.5$ & 0.07 & $-1.1-0.7$ & 0.2411 \\
\hline $3.5-5.2$ & 58 & $3.8 \pm 0.6$ & $4.0 \pm 0.4$ & 0.26 & $-0.7-1.3$ & $0.000 I^{*}$ \\
\hline$>5.2$ & 13 & $5.6 \pm 0.6$ & $5.3 \pm 0.7$ & 0.28 & $-0.4-1.2$ & 0.0619 \\
\hline
\end{tabular}

*Statistically significant. Na: Sodium; K: Potassium; ABG: Arterial blood gas

Analysis of two instruments' results only by mean difference and correlation coefficient can be misleading due to wide individual sample variation. The study by Nanda et al. seems to be flawed on this account. ${ }^{[6]}$ Method comparison by mean versus difference plot helps to understand the comparison of results better. King et al. point toward this important observation. They compared two Radiometer ABG analyzers with laboratory auto analyzer for electrolytes. The mean difference in $\mathrm{Na}^{+}$results was $1.7 \mathrm{mmol} / \mathrm{L}$ but the limit of agreement was -2.9 to $6.4 \mathrm{mmol} / \mathrm{L}$. They suggest that though the mean difference is small, but the wide limit of agreement indicate that the individual sample differences may be large. ${ }^{[14]}$

The mean between assay differences for $\mathrm{K}^{+}$was $0.16 \mathrm{mmol} / \mathrm{L}$ with the $95 \%$ limit of agreement 0.79 to $-1.07 \mathrm{mmol} / \mathrm{L}$ in the present study. Bias of more than $0.5 \mathrm{mmol} / \mathrm{L}$ was observed in $36 \%$ of samples. Budak et al. have reported the mean difference of $0.25 \mathrm{mmol} / \mathrm{L}$ with the bias in the range of $0.15-0.35$ in their study. They found $15 \%$ of samples with difference of more than $0.5 \mathrm{mmol} / \mathrm{L}$ and did not find the results to be equivalent on two instruments. ${ }^{[3]}$ Similar conclusion was drawn by Razavi et al. and Chhapola et al. ${ }^{[11,12]}$ Some other studies have reported the equivalence of results between ABG analyzer and auto analyzer..$^{[4,5,15]}$ Flegar-Mestric and Perkov who otherwise found the results equivalent have observed that in spite of a good correlation between the assays, the constant analytical errors and proportional differences between the methods indicate that two different technologies were used. ${ }^{[5]}$

Many factors may be responsible for the observed difference in $\mathrm{Na}$ and $\mathrm{K}$ results on $\mathrm{ABG}$ analyzer and electrolyte analyzer. Electrolytes results on ABG can be significantly affected by preanalytical variables such as hemolysis (especially $\mathrm{K}$ concentrations), fibrin clots within the specimen, inadequate mixing of the specimen with anticoagulant and varying the ratio of blood sample to anticoagulant. Other possible reasons could be use of conventional syringes flushed with liquid heparin which could lead to dilution of sample volume and thus underestimation of electrolytes on ABG. ${ }^{[4,12]}$ It has also been reported that the use of different types of heparin in blood gas syringes can introduce a preanalytical bias in electrolyte concentrations. Heparin itself binds the positively charged ions and can introduce different negative biases when the levels of electrolytes are measured. ${ }^{[3,16]}$

Errors in sampling technique can lead to dilution and centrifugation of samples before proper clot formation can lead to hemolysis in serum sample affecting the results of electrolytes. We did not have any control over these preanalytical variables though these errors seem unlikely as the samples were drawn by well-trained ICU staff following the standard sampling protocol. The use of different instruments with different electrodes and difference in use of calibrators could also be responsible for the observed difference in results. ${ }^{[12]}$ It is known that ISE-based instruments from different manufactures yield $\mathrm{Na}^{+}$and $\mathrm{K}^{+}$results that differ by $2-5 \% \cdot{ }^{[3]}$ Since it is a retrospective study, we are unable to correlate the results with the clinical course of patient and thus cannot comment that results of which analyzer represent it. This is another limitation of this study.

\section{Conclusions}

We conclude that the results of electrolytes on ABG and electrolyte analyzer cannot be used in inter-exchangeable manner and should be interpreted with caution. We would like to emphasize that the results obtained are specific to the instruments used. The use of dried heparin syringes may lead to better equivalence of results.

\section{Financial support and sponsorship} Nil.

\section{Conflicts of interest}

There are no conflicts of interest. 


\section{References}

1. Polandic JE. Electrolytes. In: Bishop ML, Fody EP, Schoeff LE, editors. Clinical Chemistry Techniques, Principles and Correlation. $6^{\text {th }}$ ed. New Delhi: Wolters Kluwer; 2012. p. 357-83.

2. Dimeski G, Morgan T.J, Presneill JJ, Venkatesh B. Disagreement between ion selective electrode direct and indirect sodium measurements: Estimation of the problem in a tertiary referral hospital. J Crit Care 2012;27:326.e9-16.

3. Budak YU, Huysal K, Polat M. Use of a blood gas analyzer and a laboratory autoanalyzer in routine practice to measure electrolytes in intensive care unit patients. BMC Anesthesiol 2012;12:17.

4. Jain A, Subhan I, Joshi M. Comparison of the point-of-care blood gas analyzer versus the laboratory auto-analyzer for the measurement of electrolytes. Int J Emerg Med 2009;2:117-20.

5. Flegar-Mestric Z, Perkov S. Comparability of point-of-care whole-blood electrolyte and substrate testing using a stat profile critical care xpress analyzer and standard laboratory methods. Clin Chem Lab Med 2006;44:898-903.

6. Nanda SK, Ray L, Dinakaran A. Agreement of arterial sodium and arterial potassium levels with venous sodium and venous potassium in patients admitted to intensive care unit. J Clin Diagn Res 2015;9:BC28-30.

7. Medicare, Medicaid and CLLA programs; regulations implementing the clinical laboratory improvement amendments of 1988 (CLLA) - HCFA. Final rule with comment period. Fed Regist 1992;57:7002-186.
8. Ladenson JH. Direct potentiometric measurement of sodium and potassium in whole blood. Clin Chem 1977;23:1912-6.

9. Story DA, Morimatsu H, Egi M, Bellomo R. The effect of albumin concentration on plasma sodium and chloride measurements in critically ill patients. Anesth Analg 2007;104:893-7.

10. Chacko B, Peter JV, Patole S, Fleming JJ, Selvakumar R. Electrolytes assessed by point-of-care testing - Are the values comparable with results obtained from the central laboratory? Indian J Crit Care Med $2011 ; 15: 24-9$

11. Razavi S, Jafari A, Zaker H, Sadeghi A. Plasma and serum electrolytes levels correlation in the pediatric ICU. Tanaffos 2010;9:34-8.

12. Chhapola V, Kanwal SK, Sharma R, Kumar V. A comparative study on reliability of point of care sodium and potassium estimation in a pediatric intensive care unit. Indian J Pediatr 2013;80:731-5.

13. Chow E, Fox N, Gama R. Effect of low serum total protein on sodium and potassium measurement by ion-selective electrodes in critically ill patients. Br J Biomed Sci 2008;65:128-31.

14. King R, Campbell A. Performance of the radiometer OSM3 and ABL505 blood gas analysers for determination of sodium, potassium and haemoglobin concentrations. Anaesthesia 2000;55:65-9.

15. Wongyingsinn M, Suksuriyayothin S. Use of rapid ABG analyzer in measurement of potassium concentration: Does it agree with venous potassium concentration? J Med Assoc Thai 2009;92:925-9.

16. van Berkel M, Scharnhorst V. Electrolyte-balanced heparin in blood gas syringes can introduce a significant bias in the measurement of positively charged electrolytes. Clin Chem Lab Med 2011;49:249-52. 